\title{
OBITUARY
}

\section{JAMES FISON}

It is with deep regret that we learn of the death, on April 20,1957, of Dr. James Fison, at the age of 74; his health had been failing for some months. Educated at Sidney Sussex, Cambridge, he proceeded to St. Bartholomew's Hospital. He filled postgraduate appointments, at St. Bartholomew's and Moorfields, but his career was interrupted by a period of treatment for phthisis in a sanatorium in Switzerland. In spite of this handicap, however, he joined the Royal Navy in the first World War. Thereafter, he settled in practice in Harrogate. Here he acted as ophthalmic surgeon to the Harrogate General Hospital, and the Ripon and District Hospital, and was consulting ophthalmic surgeon to the Leeds Public Dispensary and Hospital.

For his skill, knowledge, and sanity of outlook, he will be greatly missed by his colleagues, and he will be remembered with gratitude by a host of patients for his meticulous care and kindliness.

Fison was a strikingly handsome man of great charm and a fine presence; he seemed to be made of a more highly-refined metal than most of us. He was possessed of a delicate wit and took delight in all beautiful things. He was a horticulturist of no mean order, and a musician of ability; a vinery and an organ were part of the trappings of his home; at one time he was addicted to golf, at which his style-of which he professed to be inordinately proud - was more entertaining than effective: he was indeed a charming companion.

He leaves a widow, and three sons who have followed him to St. Bartholomew's, one of whom is well established in London in his father's specialty: to them we extend our deep sympathy.

\section{Alfred Clarence Norman, C.B.E.}

Dr. A. C. Norman, formerly Professor of Radiology in the Royal College of Baghdad, died at his home in Essex on April 23, 1957, at the age of 75. Although he ceased to practise ophthalmology when he was commissioned in the R.A.M.C. in 1914, it is of interest to recall that he was the first to use a silver limbal ring (about 1914) for $x$-ray localization of intra-ocular foreign bodies. 